\title{
BIOCHEMICAL CARDIAC MARKERS IN CLINICAL CARDIOLOGY
}

\author{
PALANISAMY PASUPATHI ${ }^{1}$, Y.YAGNESWARA RAO ${ }^{2}$, JAWAHAR FAROOK ${ }^{3}$, GOVINDASWAMY \\ BAKTHAVATHSALAM ${ }^{4}$
}

\begin{abstract}
Millions of patients present annually with chest pain, but only $10 \%$ to $15 \%$ have myocardial infarction. Lack of diagnostic sensitivity and specificity of clinical and conventional markers prevents or delays treatment and leads to unnecessary costly admissions. Comparative data are lacking on the new markers, yet using all of them is inappropriate and expensive. The biochemical marker determination to clinical cardiology and discusses some important developments in this field. Biochemical markers play a pivotal role in the diagnosis and management of patients with acute coronary syndrome (ACS), as witnessed by the incorporation of cardiac troponins into new international guidelines for patients with ACS and in the redefinition of myocardial infarction. Despite the success of cardiac troponins, there is still a need for the development of early markers that can reliably rule out ACS from the emergency room at presentation and also detect myocardial ischaemia in the absence of irreversible myocyte injury. The cardiac natriuretic peptides, Laboratory Medicine are also assuming a role in the assessment of cardiac function. Biochemical markers now play an important role in the detection of disease, risk stratification and the monitoring of therapy.
\end{abstract}

Keywords: Biochemical markers, Myocardial infarction, Troponin, Brain natriuretic peptide

\section{Introduction}

The clinical laboratory only placed at the cardiologist's disposal a few assays for the retrospective detection of cardiac tissue necrosis, such as enzymatic methods for creatine kinase (CK) and lactate dehydrogenase catalytic activities. ${ }^{1}$ However, in the latter part of the 20 th century, highly sensitive and specific assays for the detection of myocardial damage, such as cardiac troponins, as well as assays for reliable markers of myocardial function, such as cardiac natriuretic peptides, have become available, assigning the laboratory a pivotal role in the diagnosis and followup of patients with cardiac disease. This is witnessed by the recent incorporation of these markers into new international guidelines and in the re-definition of myocardial infarction (MI). ${ }^{2-6}$ The aim of this paper is to review the current contribution of the determination of biochemical markers to clinical cardiology and to discuss some important developments in this field.
Biochemical Markers In Clinical Cardiology
1) Aspartate aminotransferase.
2) Lactate dehydrogenase and its isoenzyme LD1
3) Creatine kinase and its isoenzyme $\mathrm{MB}$
4) Myoglobin
5) Cardiac Troponins.
6) C-reactive protein (Inflammation marker)
7) Cardiac Natriuretic Peptides

\section{Cardiac Enzymes}

As noted above, Karmen and colleagues first reported that serum glutamate oxaloacetate transaminase was

1. Head- Department of Clinical Biochemistry, Institute of Laboratory Medicine, K.G. Hospital and Post Graduate Medical Institute, Coimbatore-641 018, Tamil Nadu, India.

2. Chief-Cardiologist, Department of Cardiology, K.G. Hospital and Post Graduate Medical Institute, Coimbatore641 018, Tamil Nadu, India.

3. Consultant Cardiologist, Department of Cardiology, K.G. Hospital and Post Graduate Medical Institute, Coimbatore641 018, Tamil Nadu, India.

4. Professor, Department of Surgery, K.G. Hospital and Post Graduate Medical Institute, Coimbatore- 641 018, Tamil Nadu, India.

Correspondence : Dr. P. Pasupathi, Head, Department of Clinical Biochemistry, Institute of Laboratory Medicine, K.G. Hospital and Post Graduate Medical Institute, Coimbatore-641 018 , Tamil Nadu, India. E-mail: drppasupathi@gmail.com 
increased in patients with AMI. ${ }^{7,8}$ Assays for serum lactate dehydrogenase (LDH) and serum CK were then developed and utilized as cardiac markers, in the early 1960s, with CK gradually becoming the marker of choice as a result of its early increase after injury. ${ }^{9-10}$ Differences in substrate specificity for $\mathrm{LDH}$ isoenzymes were then used to develop assays for serum a-hydroxybutyrate dehydrogenase (HBD; LDH isoenzyme1), which showed an increased specificity for the detection of myocardial damage. ${ }^{11}$ Electrophoretic procedures were developed for the demonstration of CK and LDH isoenzymes, which were recognized as having greater specificity than total CK activity. Analytical procedures for CK-MB activity were developed following the production of antibodies to the B-subunit. ${ }^{12}$

It is now generally accepted that activity measurement of enzyme markers such as aspartate aminotransferase (AST), LDH, HBD and CK-MB is of little value in the assessment of myocardial injury, because of the lack of tissue specificity. ${ }^{13}$ The value of total CK is limited; however, it does appear in the bloodstream relatively soon after injury so it may still be of some value when it is used in combination with more sensitive markers, such as the troponins or CKMB measured by mass assay. ${ }^{14}$

\section{Creatine Kinase and CK-MB Isoenzyme}

Cytoplasmic CK is a dimer, composed of $\mathrm{M}$ and/or B subunits, which associate forming CK-MM, CK-MB and CK-BB isoenzymes. Creatine kinase acts as a regulator of high-energy phosphate production and utilization within contractile tissues; it also has a more general role in shuttling high-energy phosphate bonds via creatine phosphate from the site of ATP production in the mitochondria to the site of utilization within the cytoplasm. ${ }^{15}$ This supports the observation that the enzyme is found in tissues that have high-energy requirements, such as the distal tubules of the kidney. $\mathrm{CK}$ is also found as a mitochondrial form; mitochondrial CK is also a dimer, consisting of sarcomeric and non-sarcomeric subunits. ${ }^{16}$ Mitochondrial CK is unstable in human serum, difficult to measure and consequently its clinical significance is unknown. CK-MM is the main isoenzyme found in striated muscle (approximately $97 \%$ of the total CK). CK-MB is found mainly in cardiac muscle, where it comprises $15 \pm 40 \%$ of the total CK activity, with the remainder being CK-MM. Trace amounts of CK-MB are found in skeletal muscle $(2 \pm 3 \%$ of the total CK activity); patients with skeletal muscle injury will have increases in the absolute concentrations of CK and CK-MB. CK-BB is the predominant isoenzyme found in brain, colon, ileum, stomach and urinary bladder. ${ }^{17}$

The development of antibodies to the M-subunit of CK enabled immunoinhibition to be used as the first specific quantitative assay for CK-MB. ${ }^{18}$ The antibodies inhibit M-subunit activity, with residual enzyme activity being derived from B-subunits only; CK-BB is undetectable by activity measurement in serum, unless the patient has suffered a severe cerebrovascular accident, and so the residual activity represents CK-MB activity. Although antibodies had been developed to the B- and M-subunits of CK, it was thought that MB did not have its own unique antigenicity. However, specific antibodies were developed in the mid- $1980 \mathrm{~s},{ }^{19}$ allowing the development of direct immunological assays for CKMB.

Serum total CK activity and CK-MB concentration rise in parallel following myocardial injury, starting to increase $4 \pm 6 \mathrm{hr}$ after injury, reaching peak serum concentrations after $12 \pm 24 \mathrm{hr}$ and returning to baseline after $48 \pm 72 \mathrm{hr} .{ }^{20}$ Serum CK-MB is considerably more specific for myocardial damage than is serum total CK, which may be elevated in many conditions where skeletal muscle is damaged. Consequently, CK should not be used for the diagnosis of myocardial injury unless used in combination with other more specific cardiac markers. ${ }^{21}$ The retention of serum total CK can also be justified for clinical trials and epidemiological studies, as often it has been the only marker used in a number of clinical trials. ${ }^{22}$ The diagnostic specificity of serum CK-MB for the detection of AMI has been reported to be very close to $100 \%,{ }^{23}$ while that of CK is only approximately $70 \%$.

\section{Creatine Kinase Isoforms}

The M-subunit of creatine kinase was found to exist in plasma in multiple forms, despite the single form of MM or MB found in tissue. ${ }^{24}$ Three forms of the MM isoenzyme and two forms of the MB isoenzyme were subsequently identified and purified from plasma. In the case of CK-MM, the tissue isoform was designated CK-MM3; the plasma enzyme carboxypeptidase-N catalyses the removal of a carboxyterminal lysine residue from one of the $\mathrm{M}$ subunits to give the isoform CK-MM2. Removal of the lysine residue from the remaining $\mathrm{M}$ subunit by the same 
mechanism gives rise to the third isoform, CK-MM1. For CK-MB, the tissue form is designated CK-MB2; removal of the lysine residue from the carboxy terminus of the single M-subunit, catalysed by the action of carboxypeptidase- $\mathrm{N}$, gives rise to the CKMB1 isoform. Removal of the lysine residue, which is positively charged, leaves a more negatively charged isoform, providing a basis for separation of the isoforms by electrophoresis. ${ }^{25}$ The B-subunit is not susceptible to enzymic degradation, so only two isoforms of CKMB exist.

In normal plasma, CK-MB isoforms exist with each other in equilibrium, in a 1:1 ratio. Release of tissue CK-MB2 increases its proportion in plasma; a change in the ratio of CK-MB2: CK-MB1 from 1:1 to 2:1 can be detected using high-voltage gel electrophoresis, even though there is no significant change in the plasma concentration of CKMB. ${ }^{25}$ Significant changes in the ratio of the two isoforms in plasma can be detected between 2 and $4 \mathrm{~h}$ after myocardial injury. Systematic prospective studies have confirmed CK-MB isoforms as an early marker of myocardial injury, and established a CK-MB2: CK-MB1 ratio above 1.5:1 as a diagnostic criterion. ${ }^{26,27}$ The isoform ratio returns too normal within $18 \pm 30 \mathrm{hr}$ after injury. It has been suggested that a normal 1:1 isoform ratio in a sample collected at least $6 \mathrm{~h}$ after an event effectively excludes a diagnosis of myocardial infarction (MI). The rapid return to normal values makes the CK-MB isoforms the best available laboratory investigation for the confirmation of reinfarction. ${ }^{27}$ Unfortunately, the analytical procedure used (high-voltage gel electrophoresis) requires specialist equipment and a great deal of technical expertise, and is therefore impractical for routine use. In addition, skeletal muscle contains trace amounts of CK-MB, so skeletal muscle damage will cause an increase in the CK-MB isoform ratio.

\section{Currently Used Biomarkers \\ Myoglobin}

Myoglobin was the first non-enzymatic protein used for diagnosis of AMI, dating back to the 1970s. As a small molecule $(17.8 \mathrm{kDa})$, its quick release into circulation as early as $1 \mathrm{hr}$ upon symptom onset with high sensitivity and high negative predictive value (NPV) makes myoglobin a valuable early screening test for AMI. ${ }^{28}$ However, the clinical specificity of myoglobin is poor due to its abundant presence not only in myocardial but also in skeletal muscle cells. Therefore, injury in skeletal muscle may also trigger an elevation in the plasma concentration of myoglobin. ${ }^{29}$

\section{Cardiac Troponin}

Troponin is the biomarker of choice for the detection of cardiac injury. To use it properly, one must understand how sensitive the specific assay being used is for detecting cardiac injury, the fact that elevated troponin levels are highly specific for cardiac injury and some critical issues related to the basic science of the protein and its measurement. In this article, we review the biology of troponin, characteristics of assays that measure serum troponin levels and how to apply these measurements to patients who present with possible cardiovascular disease. We also discuss other clinical situations in which troponin levels may be elevated.

Since the first report on the measurement of cTnT in $1989,{ }^{30}$ followed by the subsequent description of the measurement of cTnI in 1992, ${ }^{31}$ there has been a revolution in the cardiac marker measurements. Due to their great sensitivity and specificity for myocardial cell damage, cardiac troponins (cTnI, cTnT) have been considered as the "gold standard" for AMI diagnosis. ${ }^{32,33}$ The early release kinetics of troponins following AMI are similar to CK-MB in that it takes several hours for both of them to be released into circulation before being detectable, hence both cardiac troponins cannot be used as early markers. However, of the current cardiac markers, troponins are the most cardiac-specific and offer the widest temporal diagnostic window. They remain abnormal for 4-10 days after the onset of AMI, ${ }^{34}$ with the peak concentration closely correlated with the infarct size. ${ }^{35,36}$ The advantages of cardiac troponins have been highlighted by their roles in cardiospecific diagnosis, risk stratification, prognostic risk assessment, and therapeutic choices. ${ }^{33,37}$ For instance, the CAPTURE study has demonstrated the benefit of anti-platelet treatment with glycoprotein IIb/ IIIa receptor antagonists to the patients with elevated cTnT levels. ${ }^{38}$ On the other hand, the specificity of troponins for ACS has recently been questioned, because other clinical situations, such as sepsis, hypovolemia, renal failure, etc., may also cause an increase in troponin level ${ }^{39}$

A qualitative result could be provided within a few minutes with a well-validated bedside test, making diagnosis in particular settings (i.e. emergency rooms or chest pain units) possible without involving of the 
Table-I

Biochemical markers of cardiac injury.

\begin{tabular}{lccc}
\hline Marker & Time to raised plasma value & Peak & Duration of elevation \\
\hline Aspartate aminotransferase & $8 \pm 12 \mathrm{~h}$ & $1 \pm 2$ days & $3 \pm 6$ days \\
Lactate dehydrogenase & $8 \pm 12 \mathrm{~h}$ & $2 \pm 3$ days & $7 \pm 10$ days \\
Creatine kinase & $4 \pm 6 \mathrm{~h}$ & $12 \pm 36 \mathrm{~h}$ & $3 \pm 4$ days \\
Hydroxybutyrate dehydrogenase & $8 \pm 12 \mathrm{~h}$ & $2 \pm 3$ days & $7 \pm 14$ days \\
CK-MB (activity) & $4 \pm 6 \mathrm{~h}$ & $12 \pm 24 \mathrm{~h}$ & $2 \pm 3$ days \\
CK-MB (mass) & $4 \pm 6 \mathrm{~h}$ & $12 \pm 24 \mathrm{~h}$ & $2 \pm 3$ days \\
CK isoforms & $1 \pm 3 \mathrm{~h}$ & $8 \pm 12 \mathrm{~h}$ & $18 \pm 30 \mathrm{~h}$ \\
Myoglobin & $2 \pm 3 \mathrm{~h}$ & $6 \pm 12 \mathrm{~h}$ & $24 \pm 48 \mathrm{~h}$ \\
Heart fatty acid binding protein & $2 \pm 3 \mathrm{~h}$ & $8 \pm 10 \mathrm{~h}$ & $18 \pm 30 \mathrm{~h}$ \\
Myosin light chains & $3 \pm 6 \mathrm{~h}$ & 4 days & $10 \pm 14$ days \\
Troponin T & $4 \pm 6 \mathrm{~h}$ & $12 \pm 24 \mathrm{~h}$ & $7 \pm 10$ days \\
Troponin I & $4 \pm 6 \mathrm{~h}$ & $12 \pm 24 \mathrm{~h}$ & $6 \pm 8$ days \\
\hline
\end{tabular}

central laboratory, and thus allowing for more rapid clinical decisions. ${ }^{40,41}$ Because of its characteristics as the 'ideal' biochemical marker of acute myocardial damage, cTns have today a definite role in the diagnostic and in the prognostic assessment of patients with acute coronary syndromes. ${ }^{42-46}$ Further studies have been conducted to determine the usefulness of these markers in the diagnosis of myocardial cell damage of non-ischaemic origin and in the detection of myocardial injury in patients undergoing cardiac and non-cardiac surgery. ${ }^{47-52}$

\section{The Emergency Department}

Patients who present with chest pain, in whom unstable coronary disease is possible but not overt, are at higher risk of cardiac events if troponin is elevated. In a landmark study, Hamm and colleagues evaluated the effectiveness of rapid triage using bedside tests to detect cTnI and cTnT in 733 patients with acute chest pain in an emergency department as long as one sample was obtained at least 6 hours after the onset of symptoms. Patients with normal troponin values had a negligible incidence of events over a 30day follow-up ${ }^{53}$. The assays used in that study were less sensitive than contemporary assays. In another study involving patients who presented with chest pain but who had normal ECGs, coronary artery disease was found in $90 \%$ of those with an elevated troponin level and in $23 \%$ of those with a normal troponin level $(p<0.001)$. Had the 99th percentile been used instead of the much higher ROC cut-off value for the troponin levels, even more patients with coronary artery disease would likely have been identified. When using low cut-off values for patients with a low pretest probability of disease, it is important to understand that analytical false-positive results may occur owing to imprecision of the assays at low levels.

\section{Cardiac Inflammation Markers}

Atherosclerosis is associated with an inflammatory process, and markers of inflammation are being investigated as potential tools for cardiovascular risk prediction. Many studies have suggested that highsensitivity C-reactive protein (CRP) is a useful predictor of cardiovascular risk. ${ }^{53}$ However, there are serious limitations to the use of CRP, due to the large intra-individual variation in plasma concentration, which can lead to misclassification of risk status ${ }^{54}$. Interleukin-18 (IL-18) is known to be involved with atherosclerotic plaque progression and its vulnerability for rupture. As a substudy of the Prospective Epidemiological Study of Myocardial Infarction (PRIME) study, baseline plasma IL-18 concentrations were shown to be significantly higher in patients experiencing a coronary event than those who did not. Baseline IL-18 was shown to be associated with future coronary events, independently of other risk factors and other markers of inflammation. ${ }^{55}$ More studies are needed to determine the potential clinical value of IL-18 as a marker of cardiovascular risk. 
Myeloperoxidase (MPO) is a haem-containing enzyme, abundant in polymorph nuclear neutrophils. Infiltration by these leukocytes is seen in the damaged atherosclerotic plaques associated with acute coronary syndromes. Leukocyte activation, seen in the plaques, is associated with the release of MPO, leading to the formation of oxygen free radicals, promoting an inflammatory response. Serum MPO has been shown to be an independent cardiovascular risk factor in patients with chest pain but with a negative serum TnT (i.e. patients with no evidence of myocardial necrosis on presentation) ${ }^{56}$ It may be that MPO is not only a marker, but also a direct contributor to the inflammatory process. Further studies are required to evaluate MPO as a predictor of risk, and as a possible target for pharmacological manipulation.

\section{Cardiac Natriuretic Peptides}

The last part of this review is devoted to consider the role and the importance that biomarkers are assuming in the clinical assessment of cardiac function. This is an area where biochemical tests have traditionally not played any role. With the recent clinical characterization of cardiac natriuretic peptides, this promises to be an emerging field of Laboratory Medicine. Natriuretic hormones are a family of related peptides with similar peptide chains as well as degradation pathways. Cardiac natriuretic peptides include atrial natriuretic peptide (ANP) and B-type natriuretic peptide (BNP), while other natriuretic peptides, such as C-type natriuretic peptide and urodilatin, are not produced and secreted by cardiac tissue but by other tissues. ${ }^{56} \mathrm{ANP}$ and BNP derive from precursors, the pre-pro-hormones, which contain a signal peptide sequence at the $\mathrm{N}$ terminal end, ${ }^{57}$ The pro-hormones are further split into inactive $\mathrm{N}$ terminal fragments and the biologically active peptide hormones. ${ }^{57}$

Whereas ANP is secreted mainly from atrial cardiomyocytes, BNP is preferentially produced and secreted in the left ventricle, although this may be a simplification, as the right side of the human heart also synthesises and secretes BNP in response to disease. ${ }^{58}$ The precise mechanisms controlling production and secretion of cardiac natriuretic peptides are still unclear, although ventricular stretch and wall tension are likely to be important. ${ }^{56}$ In general, the plasma concentrations of these peptides are increased in diseases characterised by an expanded fluid volume, such as renal failure, primary aldosteronism and congestive heart failure (CHF), or by stimulation of peptide production caused by ventricular hypertrophy or strain, thyroid disease, excessive circulating glucocorticoid or hypoxia. ${ }^{59} \mathrm{In}$ agreement with a recent commentary ${ }^{60}{ }^{6}$ it is therefore surprising that researchers focused for so long on the single issue of whether cardiac natriuretic peptides identified left ventricular (LV) systolic dysfunction or not and did not recognise that these peptides should be used in a more general way in order to detect all cardiac abnormalities, including LV hypertrophy, LV diastolic dysfunction, atrial fibrillation and significant cardiac valve disease. It is now clear that measurement of cardiac natriuretic peptides in plasma does not unequivocally diagnose the specific underlying cause of a myocardial dysfunction but ratherverify the need for further cardiac examination. ${ }^{61} \mathrm{High}$ concentrations of these markers call for further investigations: echocardiography is therefore required to identify the underlying cardiac pathology, revealing the systolic and diastolic ventricular function and thus determining the appropriate treatment. This was instrumental for the ESC to incorporate cardiac natriuretic peptides in the first step for the evaluation of symptomatic patients suspected of having CHF. ${ }^{62}$

Although the reliable role of cardiac natriuretic peptides in the identification and management of patients with symptomatic and asymptomatic ventricular dysfunction remains to be fully clarified, the clinical usefulness of cardiac natriuretic peptides (especially BNP and Nt-proBNP) in the evaluation of patients with suspected heart failure, in prognostic stratification of patients with $\mathrm{CHF}$, in detecting $\mathrm{LV}$ systolic or diastolic dysfunction and in the differential diagnosis of dyspnoea has been confirmed even more recently. ${ }^{63} \mathrm{BNP}$ and Nt-pro BNP have also emerged as prognostic indicators of long-term mortality early after an acute coronary event.

This association was observed across the spectrum of ACS, including patients with ST-elevation MI (STEMI), NSTEMI and unstable angina, those with and without elevated cardiac troponins, and those with and without clinical evidence of heart failure ${ }^{64,65}$. However, more work remains to be carried out to determine the optimal decision limits for clinical interpretation, as well as the specific therapeutic strategies of persistent cardiac natriuretic peptide elevation in these patients. Quite recently, plasma natriuretic peptide concentrations were also related to risk of cardiovascular events and death in apparently 
asymptomatic persons. ${ }^{66}$ Important issues related to the clinical use of cardiac natriuretic peptides are still open. ${ }^{67} \mathrm{~A}$ working list could include: the need of standardisation of cardiac natriuretic peptide immunoassays and of better definition of their analytical performance, with regard to the antibody specificity, calibrator characterisation and influence of pre-analytical factors; more complete understanding of cardiac secretion, molecular heterogeneity and metabolism of cardiac natriuretic peptides and knowledge of their biological variation; and, from the clinical point of view, possible differences between BNP and Nt-proBNP, definition of optimal decision limits and use in combination with other biochemical markers, clinical findings, or haemodynamic parameters. Additional studies are also needed to analyse the clinical relevance of cardiac natriuretic peptides in the patient follow-up, as well as their costeffectiveness in different clinical settings.

\section{Conclusions}

Sophisticated biochemical markers have become increasingly important in the investigation of myocardial injury. It is 50 years since the first enzyme markers were reported to be an aid to the detection of myocardial necrosis. Over the ensuing 50 years, there has been a progressive improvement in the tissue specificity of biomarkers, and in their clinical sensitivity and specificity. Over the last 50 years, the contribution of Laboratory Medicine to the management of cardiac diseases has become increasingly sophisticated. ${ }^{68}$ In the 1950 s, Karmen et al. ${ }^{69}$ first reported that enzyme release from necrotic cardiac myocytes could be detected in the serum and could aid in the diagnosis of MI. The ensuing years witnessed progressive improvement in the cardiac tissue specificity of biochemical markers and a corresponding enhancement in the clinical sensitivity and specificity of their use. For the foreseeable future, proteomic research for novel biomarker discovery is likely to give further significant contributions. There is now accumulating evidence that a multi-marker strategy, employing a path-biologically diverse set of biomarkers, is likely to help significantly in the assessment of patients with cardiac disease. ${ }^{70}$ In particular, markers of plaque destabilisation and/or markers of myocardial ischaemia could be added to the existing markers of cardiac necrosis and function in this paradigm if shown to contribute additional independent information. Biochemical markers now play an important role in the detection of disease, risk stratification and the monitoring of therapy.

\section{References}

1. Collinson PO. Early diagnosis of myocardial infarction: why measure cardiac enzymes? J Clin Pathol 1998; 51: 2-4.

2. Braunwald E, Antman EM, Beasley JW et al. ACC/ AHA guidelines for the management of patients with unstable angina and non-STsegment elevation myocardial infarction: a report of the American College of Cardiology/American Heart Association task force on practice guidelines (Committee on the management of patients with unstable angina). J Am Coll Cardiol 2000; 36:970-1062.

3. Bertrand ME, Simoons ML, Fox KAA et al. Management of acute coronary syndromes in patients presenting without persistent STsegment elevation. Eur Heart J 2002; 23:1809-1840.

4. Hamm CW, Bertrand M, Braunwald E. Acute coronary syndrome without ST elevation: implementation of new guidelines. Lancet 2001; 358:1533-1538.

5. Remme WJ, Swedberg K. Guidelines for the diagnosis and treatment of chronic heart failure. Eur Heart J 2001; 22:1527-1560.

6. Alpert J, Thygesen K for the Joint European Society of Cardiology/ American College of Cardiology Committee. Myocardial infarction redefined - a consensus document of the Joint European Society of Cardiology/American College of Cardiology Committee for the Redefinition of Myocardial Infarction. Eur Heart J 2000;21:1502-1513.

7. Karmen A, Wrobleski F, La Due JS. Transaminase activity in human blood. J Clin Invest 1954; 34: 12633.

8. LaDue JS, Wrobleski F, Karmen A. Serum glutamic oxaloaxetic transaminase activity in human acute transmural myocardial infarction. Science 1954; 120: 497-502.

9. Amador E, Dorfman LE, Wacker WE. Serum lactic dehydrogenase activity: an analytical assessment of current assays. Clin Chem 1963; 9: 391.

10. Dunn RJ, Siegel AL. Serum creatine phosphokinase in acute myocardial infarction. Arch Intern Med 1965; 115: 443-551.

11. Elliot BA, Jepson EM, Wilkinson H. Serum alpha hydroxybutyrate dehydrogenase: a new test with improved specificity for myocardial lesions. Clin Sci 1962; 23: 305-316. 
12. Jockers-Wretou E, $\mathrm{P}^{-}$eiderer G. Quantitation of creatine kinase isoenzymes in human tissues and sera by an immunological method. Clin Chim Acta 1975; 58: 223-232.

13. Alpert JS, Thygesen KE, for the joint European Society of Cardiology/American College of Cardiology Committee. Myocardial infarction redefined -a consensus document of the Joint European Society of Cardiology/American College of Cardiology Committee for the Redefinition of Myocardial Infarction. Eur Heart J 2000; 21: 1502-1513.

14. Wu AHB, Apple FS, Gibler WB, Jesse RL, Warshaw MM, Valdes R. National Academy of Clinical Biochemistry Standards of Laboratory Practice: Recommendations for the use of cardiac markers in coronary artery disease. Clin Chem 1999; 45: 11041121.

15. Bessman SP, Carpenter CL. The creatine-creatine phosphate energy shuttle. Ann Rev Histochem 1985; 54: 831-62.

16. Klein SC, Haas RC, Perryman MB, Billadello JJ, Strauss AW. Regulatory element analysis and structural characterisation of the human sarcomeric mitochondrial creatine kinase gene. J Biol Chem 1991; 266: 18058-61.

17. Lott JA, Nemesanszky E. Creatine kinase. In: Lott JA, Wolf PL, eds. Clinical Enzymology: a Caseorientated Approach. New York: Field and Rich/ Yearbook, 1996; 166.

18. Jockers-Wretou E, $\mathrm{P}^{-}$eiderer G. Quantitation of creatine kinase isoenzymes in human tissues and sera by an immunological method. Clin Chim Acta 1975; 58: 223-232.

19. Vaidya HC, Maynard Y, Dietzler DN, Ladenson JH. Direct measurement of creatine kinase-MB activity in serum after extraction with a monoclonal antibody specific to the MB isoenzyme. Clin Chem 1986; 32: $657-663$.

20. Homburg JJ, Friedman DL, Perryman MB. Metabolic and diagnostic significance of creatine kinase isoenzymes. Trends Cardiovasc Med 1991; 1: $195-200$.

21. Jaffe AS, Ravkilde J, Roberts R, et al. Its time for a change to a troponin standard. Circulation 2000; 102: $1216-1220$.

22. Fromm RE, Roberts R. Sensitivity and specificity of new serum markers for cardionecrosis. Curr Probl Cardiol 2001; 26: 247-284.

23. Collinson PO, Stubbs PJ, Kessler AC. Multicentre evaluation of the diagnostic value of troponin $\mathrm{T}$,
CKMB mass, and myoglobin for assessing patients with suspected acute coronary syndromes in routine clinical practice. Heart 2003; 89: 280-286.

24. Wevers RA, Delsing M, Klein-Gebbink JA, Soons JB. Post synthetic changes in creatine kinase isoenzymes. Clin Chim Acta 1978; 86: 323-327.

25. Puleo PR, Guadagno PA, Roberts R, Perryman MB. Sensitive, rapid assay of subforms of creatine kinase MB. Clin Chem 1989; 35: 1452-1455.

26. Puleo PR, Meyer D, Walther C, Tawa CB, Wheeler $\mathrm{SH}$, Hamburg RJ. Use of rapid assay of subforms of creatine kinase MB to diagnose or rule out acute myocardial infarction. N Engl J Med 1994; 331: 561566.

27. Wu AHB, Apple FS, Gibler WB, et al. Diagnostic marker cooperative study for the diagnosis of myocardial infarction. Circulation 1999; 99: 16711677.

28. Brogan Jr GX, Friedman S, McCuskey C, et al. Evaluation of a new rapid quantitative immunoassay for serum myoglobin versus CK-MB for ruling out acute myocardial infarction in the emergency department. Ann Emerg Med 1994;24:665-671.

29. Storrow AB, Gibler WB. The role of cardiac markers in the emergency department. Clin Chim Acta 1999;284:187-196.

30. Katus HA, Remppis A, Looser S, Hallermeyer K, Scheffold T, Kubler W. Enzyme linked immunoassay of cardiac troponin $\mathrm{T}$ for the detection of acute myocardial infarction in patients. $\mathrm{J}$ Mol Cell Cardiol 1989;21: 1349-1353.

31. Bodor GS, Porter S, Landt S, Ladenson JH. Development of monoclonal antibodies for an assay of cardiac troponin-I and preliminary results in suspected cases of myocardial infarction. Clin Chem 1992; 38:2203-2214.

32. Alpert JS, Thygesen K, Antman E, et al. Myocardial infarction redefineda consensus document of The Joint European Society of Cardiology/ American College of Cardiology Committee for the redefinition of myocardial infarction. J Am Coll Cardiol 2000;36:959-969.

33. Babuin L, Jaffe AS. Troponin: the biomarker of choice for the detection of myocardial injury. Can Med Assoc J 2005;173:1191-1202.

34. Martins JT, Li DJ, Baskin LB, Jialal I, Keffer JH. Comparison of cardiac troponin I and lactate dehydrogenase isoenzymes for the late diagnosis of myocardial injury. Am J Clin Pathol 1996;106:705708. 
35. Licka M, Zimmermann R, Zehelein J, et al. Troponin $\mathrm{T}$ concentrations 72 hours after myocardial infarction as a serological estimate of infarct size. Heart 2002; 87:520-524.

36. Panteghini M, Cuccia C, Bonetti G, et al. Singlepoint cardiac troponin $\mathrm{T}$ at coronary care unit discharge after myocardial infarction correlates with infarct size and ejection fraction. Clin Chem 2002; 48:1432-1436.

37. Newby LK, GoldmannBU, OhmanEM. Troponin: an important prognostic marker and risk-stratification tool in non-ST-segment elevation acute coronary syndromes. J Am Coll Cardiol 2003; 41:31S-6S.

38. Heeschen C, van den Brand MJ, Hamm CW, et al. Angiographic findings in patients with refractory unstable angina according to troponin $\mathrm{T}$ status. Circulation 1999; 100:1509-1514.

39. Jeremias A, Gibson CM. Narrative review: alternative causes for elevated cardiac troponin levels when acute coronary syndromes are excluded. Ann Intern Med 2005; 142:786-791.

40. Antman EM, Grudzien C, Sacks DB. Evaluation of a rapid bedside assay for detection of serum cardiac troponin T. JAMA 1995; 273: 1279-1282.

41. Heeschen C, Goldmann BU, Moller RH, Hamm CW. Evaluation of a new troponin I bedside test in acute myocardial infarction. Circulation 1996; 94 (Suppl. I): 322 (Abstract).

42. Hamm CW, Goldmann BU, Heeschen C, Kreymann G, Berger J, Meinertz T. Emergency room triage of patients with acute chest pain by means of rapid testing for cardiac troponin T or troponin I. N Engl J Med 1997; 337: 1648-1653.

43. Galvani M, Ottani F, Ferrini D et al. Prognostic influence of elevated values of cardiac troponin I in patients with unstable angina. Circulation 1997; 95: 2053-2059.

44. Ohman EM, Armstrong PW, Christenson RH et al. Cardiac troponin $\mathrm{T}$ levels for risk stratification in acute myocardial ischemia. GUSTO IIa Investigators. N Engl J Med 1996; 335: 1333-1341.

45. Antman EM, Tanasijevic MJ, Thompson B et al. Cardiacspecific troponin I levels to predict the risk of mortality in patients with acute coronary syndromes. N Engl J Med 1996; 335: 1342-1349.

46. Heindenreich PA, Alloggiamento T, Melsop K, McDonald KM, Go AS, Hlatky MA. The prognostic value of troponin in patients with non-ST elevation acute coronary syndromes: a meta-analysis. J Am Coll Cardiol 2001; 38: 478-485.
47. La Vecchia L, Mezzena G, Ometto R et al. Detectable serum troponin I in patients with heart failure of nonmyocardial ischemic origin. Am J Cardiol 1997; 80: 88-90.

48. Cardinale D, Sandri MT, Martinoni A et al. Left ventricular dysfunction predicted by early troponin I release after high dose chemotherapy. J Am Coll Cardiol 2000; 36: 517-522.

49. Lauer B, Niederau C, Kuhl U et al. Cardiac troponin $\mathrm{T}$ in patients with clinically suspected myocarditis. J Am Coll Cardiol 1997; 30: 1354-1359.

50. Carrier M, Pelletier LC, Martineau R, Pellerin M, Solymoss BC. In elective artery bypass grafting, preoperative troponin $\mathrm{T}$ level predicts the risk of myocardial infarction. J Thorac Cardiovasc Surg 1998; 115: 1328-1334.

51. Etievent JP, Chocron S, Toubin G et al. Use of myocardial troponin I as a marker of perioperative myocardial ischemia. Ann Thorac Surg 1995; 59: 1192-1194.

52. Sadony V, Korber M, Albes G et al. Cardiac troponin I plasma levels for diagnosis and quantitation of perioperative myocardial damage in patients undergoing coronary artery bypass surgery. Eur J Cardiothorac Surg 1998; 13: 57-65.

53. Morrow DA, Ridker PM. C-reactive protein, inflammation, and coronary risk. Med Clin North Am 2000; 84: 149-61.

54. Campbell B, Badrick T, Flatman R, Kanowski D. Limited clinical utility of high sensitivity plasma C-reactive protein assays. Ann Clin Biochem 2002; 39: $85-88$.

55. Blankenberg S, Luc G, Ducimetiere P, et al. Interleukin-18 and the risk of coronary heart disease in European men. Circulation 2003; 108: 2453-2459.

56. Cowie MR, Mendez GF. BNP and congestive heart failure. Progr Cardiovasc Dis 2002;44:293-321.

57. Clerico A. Pathophysiological and clinical relevance of circulating levels of cardiac natriuretic hormones: are they merely markers of cardiac disease? Clin Chem Lab Med 2002; 40:752-760.

58. Kay JD, Trichon BH, Kisslo K et al. Serum brain natriuretic peptide levels cannot differentiate pulmonary disease from left-heart failure if the right ventricle is dilated. Circulation 2003; 108:IV-397.

59. Clerico A, Iervasi G, Mariani G. Pathophysiologic relevance of measuring the plasma levels of cardiac natriuretic peptide hormones in humans. Horm Metab Res 1999; 31:487-498. 
60. Struthers AD. Introducing a new role for BNP: as a general indicator of cardiac structural disease rather than a specific indicator of systolic dysfunction only. Heart 2002; 87:97-98.

61. Struthers AD. How to use natriuretic peptide levels for diagnosis and prognosis. Eur Heart J 1999; 20:1374-1375.

62. Remme WJ, Swedberg K. Guidelines for the diagnosis and treatment of chronic heart failure. Eur Heart J 2001; 22:1527-1560.

63. Cowie MR, Jourdain P, Maisel A et al. Clinical applications of B-type natriuretic peptide (BNP) testing. Eur Heart J 2003; 24:1710-1718.

64. De Lemos JA, Morrow DA. Brain natriuretic peptide measurement in acute coronary syndromes. Ready for clinical application? Circulation 2002; 106:28682870 .

65. White HD, French JK. Use of brain natriuretic peptide levels for risk assessment in non-ST- elevation acute coronary syndromes. J Am Coll Cardiol 2003; 42:1917-1920.

66. Wang TJ, Larson MG, Levy D et al. Plasma natriuretic peptide levels and the risk of cardiovascular events and death. N Engl J Med 2004; 350: 655-663.

67. Packer MP. Should B-type natriuretic peptide be measured routinely to guide the diagnosis and management of chronic heart failure? Circulation 2003;108:2950-2953.

68. Clerico A. The increasing impact of laboratory medicine on clinical cardiology. Clin Chem Lab Med 2003; 41:871-883.

69. Karmen A, Wroblewski F, LaDue JS. Transaminase activity in human blood. J Clin Invest 1955; 34:126133.

70. Morrow DA, Braunwald E. Future of biomarkers in acute coronary syndromes. Moving toward a multimarker strategy. Circulation 2003; 108:250252 . 